\title{
Antagonism of Nutrient-Activated Conidia of Trichoderma harzianum (atroviride) P1 Against Botrytis cinerea
}

\author{
Linda Gordon Hjeljord, Arne Stensvand, and Arne Tronsmo
}

First and third authors: Department of Chemistry and Biotechnology, Agricultural University of Norway, 1432 As, Norway; and second author: Department of Plant Pathology, The Norwegian Crop Research Institute, 1432 Ås, Norway. Accepted for publication 13 August 2001.

\begin{abstract}
Hjeljord, L. G., Stensvand, A., and Tronsmo, A. 2001. Antagonism of nutrient-activated conidia of Trichoderma harzianum (atroviride) P1 against Botrytis cinerea. Phytopathology 91:1172-1180.

The effect of preliminary nutrient activation on the ability of conidia of the antagonist Trichoderma harzianum (atroviride) P1 to suppress Botrytis cinerea was investigated in laboratory, greenhouse, and field trials. Preliminary nutrient activation at $21^{\circ} \mathrm{C}$ accelerated subsequent germination of the antagonist at temperatures from 9 to $21^{\circ} \mathrm{C}$; at $\geq 18^{\circ} \mathrm{C}$, the germination time of preactivated T. harzianum $\mathrm{P} 1$ conidia did not differ significantly from that of B. cinerea. When coinoculated with $B$.

sion only at $25^{\circ} \mathrm{C}$. Application of quiescent $T$. harzianum P1 conidia to detached strawberry flowers in moist chambers reduced infection by $B$. cinerea by $\geq 85 \%$ at $24^{\circ} \mathrm{C}$, but only by $35 \%$ at $12^{\circ} \mathrm{C}$. Preactivated conidia reduced infection by $\geq 60 \%$ at $12^{\circ} \mathrm{C}$. Both quiescent and preactivated conidia significantly reduced latent infection in greenhouse-grown strawberries at a mean temperature of $19^{\circ} \mathrm{C}$, whereas only preactivated conidia were effective in the field at a mean temperature of $14^{\circ} \mathrm{C}$ on the day of treatment application. An antagonistic mechanism based on initiation of germination in sufficiently concentrated inocula suggests that at suboptimal temperatures the efficacy of Trichoderma antagonists might be improved by conidia activation prior to application.
\end{abstract} cinerea, concentrated inocula of preactivated but ungerminated $T$. harzianum $\mathrm{P} 1$ conidia reduced in vitro germination of the pathogen by $\geq 87 \%$ at 12 to $25^{\circ} \mathrm{C}$; initially quiescent conidia achieved this level of suppres-
Additional keywords: fungal ecophysiology, microhabitat, pregermination, respiration, swollen conidia.
Gray mold, caused by Botrytis cinerea Pers:Fr., is one of the most important diseases of strawberries (Fragaria $\times$ ananassa Duchesne) on a worldwide basis, which is the primary reason this crop is among those most likely to contain fungicide residues $(9,47,51)$. Public concern about such residues in edible products and the environment, augmented by the practical problems arising from fungicide resistance in $B$. cinerea, has accelerated the search for alternative disease control strategies. One such strategy is biological control (8). Because gray mold of strawberry fruits often originates from infection by $B$. cinerea during blossoming (4), prevention of blossom infection is a goal of biological as well as chemical disease control strategies $(2,52,55,59)$.

The fungal antagonist Trichoderma harzianum Rifai, alone or in combination with chemical fungicides, is capable of reducing disease caused by $B$. cinerea and other phytopathogens in a number of crops, including strawberries $(21,39,43)$. Although information on specific disease-reducing activities under field conditions is scarce, several factors necessary for effective biological control by Trichoderma antagonists have been empirically identified through field trials. These include access to exogenous nutrients $(40,43)$, a highly concentrated inoculum $(12,55)$, ambient temperatures of $\geq 20^{\circ} \mathrm{C}(17,42)$, and introduction in advance of the pathogen $(24$, $41,42,60)$.

The above observations are not unambiguously related to the antagonistic mechanisms identified to date. That Trichoderma isolates require exogenous nutrients to germinate is well established, and under nutrient-poor conditions, germination percent and rate, hyphal extension, and sporulation are all reduced $(1,10,38,44,49)$. Access to exogenous nutrients is thus assumed to enhance the

Corresponding author: L. G. Hjeljord; E-mail address: linda.hjeljord@ikb.nlh.no

Publication no. P-2001-1023-02R

(C) 2001 The American Phytopathological Society ability of this fungus to exert competitive biological control. On the other hand, Trichoderma isolates are known for their oligotrophic characteristics, and under laboratory conditions, these fungi readily colonize even extremely nutrient-poor substrates $(44,56)$. The effect of nutrient availability on antagonistic mechanisms such as antibiosis and mycoparasitism is unclear. Whereas high $\mathrm{C}: \mathrm{N}$ ratios enhance antibiotic production in many Trichoderma spp. (25), the concentrations of simple sugars or favored substrates necessary for rapid growth of $T$. harzianum inocula have been reported to repress production of enzymes putatively involved in mycoparasitism; nutrient stress may in fact be a prerequisite for expression of some cell wall-degrading enzymes $(32,34)$.

Another observation eluding simple explanation is that of the time factor involved in interactions between $T$. harzianum and rapidly germinating pathogens. Even under optimal temperature and nutrient conditions, conidia of T. harzianum isolates require 14 to $18 \mathrm{~h}$ just to complete germination and initiate mycelial extension, much less colonize a plant surface extensively enough to effectively intercept more rapidly germinating pathogens (23, 31 ). Nonetheless, coinoculating conidia of $T$. harzianum and $B$. cinerea, or inoculating $T$. harzianum only $8 \mathrm{~h}$ before $B$. cinerea, has prevented infection of wounded tissue, even though conidia of T. harzianum cannot germinate before those of the pathogen within this time $(26,42,60)$. The necessity of introducing many antagonist conidia relative to those of the pathogen is also difficult to explain. Finally, although there are many reports of disease control following application of $T$. harzianum conidia to plant surfaces, there are notably few accounts confirming their actual germination on and colonization of such substrates under field conditions (15).

The experiments presented arose from a curiosity about these observations and from the conviction that increased knowledge of interactions between $T$. harzianum and $B$. cinerea on plant surfaces will ultimately lead to more consistent and effective 
Trichoderma-based biocontrol programs. Preliminary experiments showed that in moist chambers T. harzianum P1 conidia were able to prevent infection of detached strawberry flowers by coinoculated $B$. cinerea conidia at 21 to $24^{\circ} \mathrm{C}$, but efficacy decreased at lower temperatures. These findings were consistent with the inability of several commercial T. harzianum isolates to reduce gray mold in a greenhouse maintained at 12 to $18^{\circ} \mathrm{C}$ (23). However, experiments indicated that even at temperatures at which it did prevent infection, the antagonist was not capable of germinating as quickly as the pathogen, suggesting the importance of pregermination interactions between the fungi. Further experiments were therefore designed to test the hypothesis that preliminary nutrientinduced initiation of germination would improve the capacity of $T$. harzianum conidia to inhibit germination of $B$. cinerea conidia in vitro. We tested the hypothesis that $T$. harzianum would show improved inhibition of $B$. cinerea infection of strawberry flowers in the field and greenhouse if the antagonist conidia were induced to initiate germination before application.

\section{MATERIALS AND METHODS}

Fungal isolates. The Trichoderma antagonist used in this study, strain P1 (ATCC 74058), was known as T. harzianum at the time that this paper was accepted. Although it has now been demonstrated that this strain likely belongs to the species $T$. atroviride (30), the original nomenclature was retained in this paper for consistency with our previous work as well as the literature cited. Stock cultures of T. harzianum Rifai strain P1 (ATCC 74058) (54) were stored at $-20^{\circ} \mathrm{C}$ on silica gel (48). Current cultures were grown at room temperature (RT) $\left(18\right.$ to $\left.24^{\circ} \mathrm{C}\right)$ on potato dextrose agar (PDA) (Difco Laboratories, Detroit) for 2 weeks and stored at $4^{\circ} \mathrm{C}$. Conidia from these cultures were inoculated on PDA for production of sporulating cultures for trials. B. cinerea E1, originally isolated from gray mold on strawberries in Norway, was maintained on PDA and stored at $4^{\circ} \mathrm{C}$. Both fungi readily produced conidia after 7 to 14 days on PDA at RT under regular laboratory lighting. Conidia for laboratory and greenhouse trials were obtained from 10- to 21-day-old colonies by flooding plates with sterile water and rubbing gently with a glass rod; suspensions of $B$. cinerea conidia were filtered through sterile cheesecloth before use. Conidia concentrations were determined by hemacytometer counts and diluted appropriately shortly before use.

Nutrient activation of $\boldsymbol{T}$. harzianum $\mathbf{P 1}$ conidia. In this paper, "activation" is used to indicate exposure of conidia to nutrients in order to induce initiation of germination (13), although we are aware that some authors do not consider nutrients to be germination activators in a strict sense $(20,50)$. To test the effects of nutrient activation, $1 \times 10^{7}$ T. harzianum $\mathrm{P} 1$ conidia per $\mathrm{ml}$ were incubated in $2.4 \%$ (wt/vol) potato dextrose broth (PDB) (Difco Laboratories) at $22 \pm 1{ }^{\circ} \mathrm{C}$ on a reciprocal shaker at $150 \mathrm{rpm}$ for approximately $6 \mathrm{~h}$. For use in laboratory trials, the conidia were pelleted and washed twice in sterile distilled water by centrifugation for $5 \mathrm{~min}$ at $900 \times g$, resuspended in sterile distilled water at a concentration of approximately $10^{9}$ conidia per $\mathrm{ml}$, and stored at $4{ }^{\circ} \mathrm{C}$ until use. For use in field trials, conidia were activated as described and separated from the nutrient solution by filtration over Whatman GF/C filters (Whatman International Ltd., Maidstone, England). Conidia were washed from the filters and resuspended in water in the appropriate concentrations before application. During activation, the diameter of $\geq 90 \%$ of the conidia increased from 3 to $3.5 \mu \mathrm{m}$ (quiescent conidia) to 6 to $7.5 \mu \mathrm{m}$ (swollen conidia). No germ tubes were produced during activation. Germinability of activated conidia was not impaired by spray application at a pressure of $6 \times 10^{5} \mathrm{~Pa}$ (data not shown).

In vitro germination assays. Germination of $T$. harzianum and $B$. cinerea isolates in vitro was investigated by incubating conidial suspensions in 96-well, flat bottom microtiter plates under conditions indicated in each experiment. After $24 \mathrm{~h}$, germination was assessed visually with a microscope (Leitz Fluovert FU; Ernst Leitz Wetzlar GmbH, Wetzlar, Germany) at $\times 400$ magnification. A minimum of 100 randomly selected conidia in each of two replicate wells per treatment were evaluated and counted as germinated when the germ tube exceeded the diameter of the conidium. When necessary for practical purposes, germination was stopped by addition of glutaraldehyde to a final concentration of $2.5 \%$ ( $\mathrm{vol} / \mathrm{vol})$.

T. harzianum and $B$. cinerea conidia in aqueous inocula settle out of suspension fairly quickly, e.g., B. cinerea conidia settle on the bottom of microtiter plate wells within $30 \mathrm{~min}$ of inoculation. To investigate how dense accumulations of $T$. harzianum conidia might affect germination of $B$. cinerea conidia, various concentrations of $T$. harzianum conidia were coinoculated with $B$. cinerea conidia in microtiter plate wells containing PDB. In order to accurately register germination percent in concentrated suspensions, 5- to $10-\mu \mathrm{l}$ samples were aspirated by micropipette from the floor of the wells and transferred to fresh wells containing $100 \mu \mathrm{l}$ of $2.5 \%$ glutaraldehyde. In mixed suspensions, swollen $T$. harzianum conidia were distinguished from $B$. cinerea conidia based on morphology (diameters of $\leq 8$ and $\geq 12 \mu \mathrm{m}$, respectively).

To study the effect of pollen on germination of T. harzianum, anthers were removed from newly opened strawberry flowers, placed in sterile distilled water ( $10 \mu \mathrm{l}$ per anther), and incubated for $24 \mathrm{~h}$ at $4^{\circ} \mathrm{C}$. The resulting extract was sterilized by filtration and mixed with an equal volume of a suspension of $2 \times 10^{5} \mathrm{~T}$. harzianum conidia ml ${ }^{-1}$ in microtiter plate wells. Germination was determined after $24 \mathrm{~h}$ and compared with germination in dilutions of PDB assayed in the same experiment.

Detached flower assays. Strawberry flowers (cv. Korona) were grown in hanging flats in a commercial greenhouse (Svein Grimsby, Østfold County, Norway). For use in trials, flowers of various developmental stages were collected in plastic bags, transported to the laboratory, and treated within $4 \mathrm{~h}$ of collection. In the laboratory, flowers were sprayed to runoff with a suspension of $T$. harzianum $\mathrm{P} 1$ conidia $\left(5 \times 10^{6} \mathrm{ml}^{-1}\right)$ or water (controls) and inoculated with 10- $\mu$ d droplets of $B$. cinerea E1 conidia $\left(2 \times 10^{5} \mathrm{ml}^{-1}\right)$ placed on the flower at the junction between the base of the petals and the immature fruit receptacle. Available pollen immediately covered the surface and subsequently settled to the bottom of such droplets. This method of inoculation was determined by preliminary tests to result in consistent infection by $B$. cinerea in newly opened flowers. Treated flowers were placed aseptically in sterile petri dishes, which were sealed with Parafilm and incubated at RT (approximately $22^{\circ} \mathrm{C}$ ), unless otherwise indicated. Five flowers were placed in each dish, 25 flowers per treatment. The flowers were inspected daily with a stereomicroscope for signs of sporlation of the relevant fungal isolate on the flower tissues. Appropriate controls were included to confirm that antagonist conidia were not spread to untreated flowers during treatment or incubation and to ascertain natural infection by $B$. cinerea. Each experiment was carried out at least twice, and the results shown are typical of all repetitions.

Field and greenhouse trials. The field trial was carried out on third-year strawberry plants (cv. Korona) at a commercial strawberry plantation (Hans Birger Stensrud, Akershus County, Norway) in June and July 2000 . The rows were spaced $150 \mathrm{~cm}$ apart and fertilized twice before flowering with $70 \mathrm{~kg}$ per ha of NPK 11-5-17 (Norsk Hydro, Oslo, Norway). Before the single application of antagonists late in the blossoming period (19 June), individual flowers were tagged with color-coded wire markers according to four phenologically defined stages: white bud, newly opened flower, old flower (losing petals, with senescent stamens), and small green fruit (unexpanded receptacle). Fifteen flowers at each stage in each of four replicates per treatment were tagged, i.e., a total of 240 flowers per treatment, in a randomized complete block design. Plants were sprayed in the evening after tagging with a suspension of $B$. cinerea E1 conidia, followed in 
less than $1 \mathrm{~h}$ by suspensions of quiescent or activated T. harzianum P1 conidia or water. Uninoculated controls were sprayed with water. Five liters of solution were used for each treatment (approximately $70 \mathrm{ml}$ per plant), applied as a spray by a manually powered backpack sprayer. Approximately $3 \mathrm{~h}$ before application, T. harzianum conidia were washed from PDA plates with sterile water as a concentrated suspension and diluted in tap water to $1 \times$ $10^{7}$ conidia $\mathrm{ml}^{-1}$ immediately before application. A concentrated suspension of activated $T$. harzianum conidia was prepared as described previously and diluted in tap water to $1 \times 10^{7}$ conidia ml ${ }^{-1}$ immediately before application. $B$. cinerea conidia were washed from plates as a concentrated suspension $1 \mathrm{~h}$ before use, filtered through sterile cheesecloth, and diluted in tap water to $1 \times$ $10^{5}$ conidia $\mathrm{ml}^{-1}$ immediately before application.

All berries in the experimental field were harvested six times at 3- to 7-day intervals, beginning 14 days after treatment. Weights of healthy and rotten berries and incidence of $B$. cinerea infection were recorded at harvest. Tagged berries were collected as they ripened, and incidence of healthy and rotten fruit was registered. The ability of $T$. harzianum P1 to colonize flowers and fruits at various times following field treatment was investigated at $18 \mathrm{~h}$, 14 and 39 days after application. At the first two sampling times, 10 flowers or apparently healthy fruits were collected from each treatment replicate, placed in petri dishes or plastic berry con-
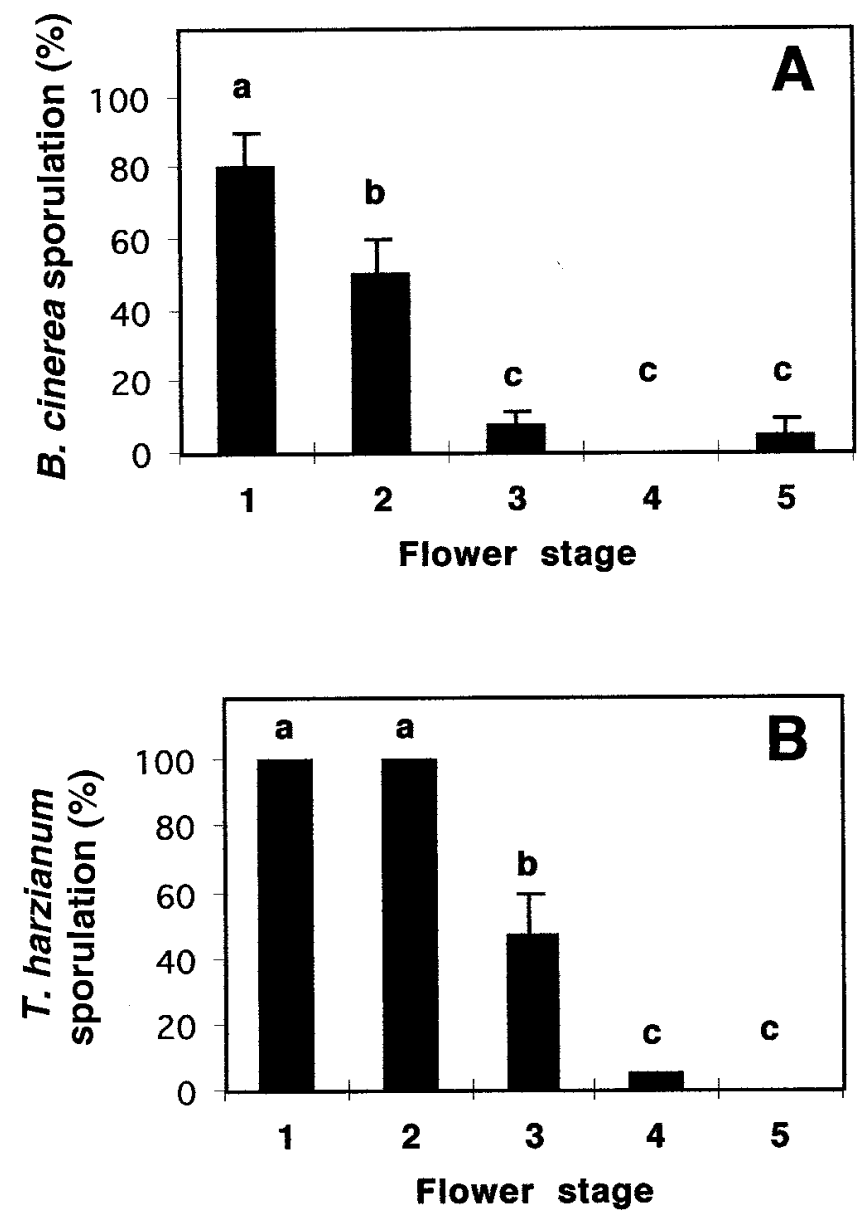

Fig. 1. Effect of flower stage on colonization by Trichoderma harzianum and Botrytis cinerea. Flower stage 1: newly opened flower; 2: flowers losing petals; 3: flowers with brown stamens and stigmas; 4: green receptacles; and 5: uninoculated new flowers. A, Percentage of flowers showing $B$. cinerea sporulation after inoculation with $B$. cinerea conidia and incubation in moist chambers for 7 days. B, Percentage of flowers showing T. harzianum P1 sporulation after sprayed to runoff and incubated in moist chambers for 4 days. Data bars indicate means with standard error. Data bars with different letters are significantly different (Fisher's protected least significant difference, $P<0.05)$. tainers, respectively, and incubated in moist chambers. Care was taken to prevent contact infection during incubation. All tagged berries in the final harvest were similarly incubated. Samples were inspected daily with a stereomicroscope for signs of Trichoderma sporulation.

The greenhouse trial was carried out in October and November 2000 on first-year strawberry plants (cv. Korona) grown in hanging flats of sphagnum peat in a commercial greenhouse (Svein Grimsby, Østfold County, Norway). Four replicates of nineteen plants (seven plants per meter) in separate flats were used for each treatment in a randomized complete block design. Ambient temperature at the level of the plants was recorded continually during the experimental period by a thermohygrograph. The flats were heated automatically by hot water pipes suspended $10 \mathrm{~cm}$ below the flats (water temperature 35 to $40^{\circ} \mathrm{C}$ ), and roof ventilators opened at temperatures exceeding $18^{\circ} \mathrm{C}$ or relative humidity above $98 \%$. A minimum day length of $18 \mathrm{~h}$ was achieved by supplementing natural light with high-pressure sodium lamps at a level of 160 to $180 \mathrm{~W} / \mathrm{m}^{2}$, as measured just above the plant canopy. Plants were fertilized continuously via the drip irrigation system with a mixture of Soft Fruit Superex, NPK 14-4-27 with magnesium and micronutrients (Kekkilä Oyj, Eurajoki, Finland) and CalciNit, $15.5 \% \mathrm{~N}$ and $19 \% \mathrm{Ca}$ (Norsk Hydro AS, Oslo, Norway). The exact composition and dosage rate of the mixture were adjusted by the grower according to the developmental stage and treatment of the plants. No chemical fungicides or other pesticides were applied to the plants.

Newly opened flowers were sprayed to runoff with hand-held spray bottles five times, at 3-day intervals, with conidial suspensions of $B$. cinerea $\mathrm{E} 1\left(1 \times 10^{5}\right.$ conidia $\left.\mathrm{ml}^{-1}\right)$, followed by suspensions of quiescent or activated T. harzianum $\mathrm{P} 1\left(5 \times 10^{7}\right.$ conidia $\mathrm{ml}^{-1}$ ) or water (Botrytis-inoculated control). Uninoculated controls were sprayed with water. Berries were harvested seven times at 3- to 5-day intervals, and incidence of healthy and diseased berries was registered. Ten symptomless berries from each replicate (i.e., 40 berries per treatment) were placed in plastic berry cartons, with care taken to insure a lack of contact between berries, and incubated at 22 to $24^{\circ} \mathrm{C}$ over trays of water. Diseased berries were removed as pathogen sporulation became evident, and total incidence of infection at 3 days was recorded. This test was repeated on berries harvested 10 days later.

Ten flowers per treatment replicate were collected immediately after being treated as newly opened flowers at 4, 8, and 10 days following treatment. These were incubated and inspected for Trichoderma sporulation as described previously. Ten ripe berries per replicate from two harvests were collected and similarly incubated. Another 10 berries per replicate in the same harvests were washed in $100 \mathrm{ml}$ of sterile water containing $0.05 \%$ Triton X-100 and plated on Trichoderma-selective medium (14) for CFU counts.

Statistical analysis of data. The significance of treatments in the field and greenhouse trials was tested by analysis of variance for interaction effects, and subsequently the significance of differences between treatment means was tested by Fisher's protected least significant difference (PLSD) for treatments at each flower stage. The ability of B. cinerea or T. harzianum to colonize different flower stages in moist chambers was analyzed by PLSD. Regression was used to analyze the effect of incubation temperature and antagonist inoculum density on in vitro germination of $B$. cinerea. Analyses were performed using the statistics software packages Excel 5.0a Data Analysis Toolpak (Microsoft) and StatView 5.0.1 (SAS Institute, Inc., Cary, NC).

\section{RESULTS}

Colonization of detached strawberry flowers by $\boldsymbol{B}$. cinerea and T. harzianum P1. Because B. cinerea is known to infect newly opened strawberry flowers, it was necessary to investigate 
the ability of $T$. harzianum P1 to colonize flowers alone and in competition with the pathogen. Untreated greenhouse-grown strawberry flowers of various phenological stages were brought to the laboratory for inoculation with $B$. cinerea or $T$. harzianum P1 followed by incubation in moist chambers. Both the antagonist and the pathogen readily colonized flowers between the time of release of pollen and petal abscission. Inoculation of flowers with $B$. cinerea during this period resulted in necrotic lesions on sepals within $72 \mathrm{~h}$ and sporulation of $B$. cinerea on sepals and petals within 7 days (Fig. 1A). B. cinerea conidia inoculated on older flowers with senescing stigmas and stamens or on green receptacles did not result in infection significantly different from uninoculated controls. When sprayed on newly opened flowers, $T$. harzianum P1 was able to colonize anthers with sporulating mycelium within 4 days, in most cases preventing sporulation by indigenous fungi on these sites, as judged by microscopic inspection of flowers incubated in moist chambers. The antagonist colonized anthers of senescing flowers less well, whereas green fruit was not colonized at all following inoculation (Fig. 1B).

Germination of $T$. harzianum in pollen extract from newly opened flowers was measured and compared with germination in dilutions of the standard laboratory medium PDB (Fig. 2). The PDB concentration affected germination percent, diameter of conidia at time of germination, and diameter of the germ tubes. Halfstrength pollen extract supported germination corresponding in all three parameters to $0.24 \mathrm{~g}$ of PDB per ml. For convenience and reproducibility of results, further in vitro experiments were conducted with PDB.

T. harzianum P1 conidia were activated by incubation in PDB as described previously. These activated conidia, or untreated quiescent conidia, were sprayed on strawberry flowers, which were then inoculated with $B$. cinerea conidia and incubated in moist chambers. The percentage of coinoculated flowers subsequently showing $B$. cinerea sporulation was affected by the incubation temperature following treatment (Fig. 3). Preactivated antagonist conidia suppressed sporulation of $\mathrm{B}$. cinerea at $12^{\circ} \mathrm{C}$ significantly better than did conidia that were quiescent at the time of application ( $t$ test, $P=0.02$ ). Not only incidence but also extent of $B$. cinerea sporulation was reduced on flowers treated with both pathogen and antagonist compared with that on flowers treated with the pathogen alone (data not shown).

In vitro germination of quiescent and activated $T$. harzianum P1 and B. cinerea. The effect of temperature on antagonistic characteristics of $T$. harzianum $\mathrm{P} 1$ was investigated further by studying in vitro germination of the fungi. The $50 \%$ germination time $\left(G_{50}\right)$ of conidia of quiescent and activated T. har- zianum $\mathrm{P} 1$ and $B$. cinerea in axenic culture was significantly affected by temperature $(T)\left(G_{50}\right.$ quiescent $\mathrm{P} 1=1,631.20 T^{-1.53}[P<$ 0.001]; $G_{50}$ activated $\mathrm{P} 1=964.03 T^{-1.67}[P<0.001]$; and $G_{50} B$. cinerea $=54.48 T^{-0.70}[P<0.001]$ ) (Fig. 4). When T. harzianum P1 conidia were activated before application, their subsequent germination time did not differ significantly from that of $B$. cinerea $\mathrm{E} 1$ at temperatures of $>15^{\circ} \mathrm{C}$ ( $t$ test, $P \geq 0.09$ ). Initially quiescent conidia had a significantly longer germination time than $B$. cinerea at all temperatures tested $(P<0.01)$. The effects of temperature on germination of quiescent and activated conidia corresponded with the results of inoculation experiments on detached flowers (Fig. 3), although the antagonistic mechanism was not clear, e.g., we have never observed interference between simultaneously germinating conidia of $T$. harzianum $\mathrm{P} 1$ and $B$. cinerea E1 in vitro. Therefore, we investigated the possibility that inhibitory interactions occurred before completion of germination.

When T. harzianum conidia were sprayed on uneven plant surfaces, inoculum droplets often coalesced, resulting in large numbers of conidia accumulating in surface depressions on leaves and flowers together with pollen grains and plant debris (L. Hjeljord,

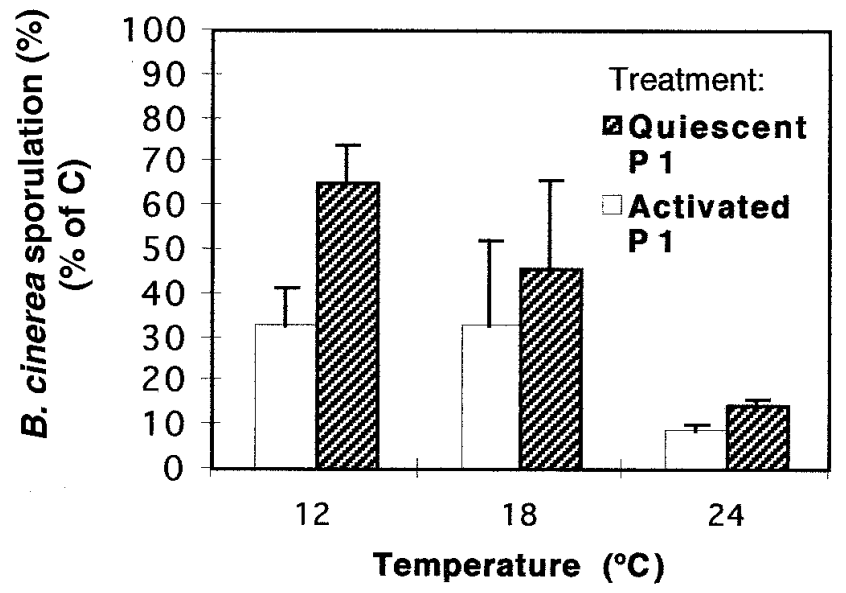

Fig. 3. The effect of temperature on the efficacy of quiescent or activated Trichoderma harzianum P1 conidia in reducing sporulation of Botrytis cinerea on strawberry flowers. Newly opened flowers were sprayed to runoff with $T$. harzianum and subsequently inoculated with $B$. cinerea. Flowers were incubated in moist chambers for 7 days at $24^{\circ} \mathrm{C}, 10$ days at $18^{\circ} \mathrm{C}$, or 14 days at $12^{\circ} \mathrm{C}$. Data bars represent incidence of sporulation on flowers treated with both pathogen and antagonist as a percentage of that on flowers inoculated with $B$. cinerea alone at the relevant temperature. Data bars represent means and standard error of three experiments.

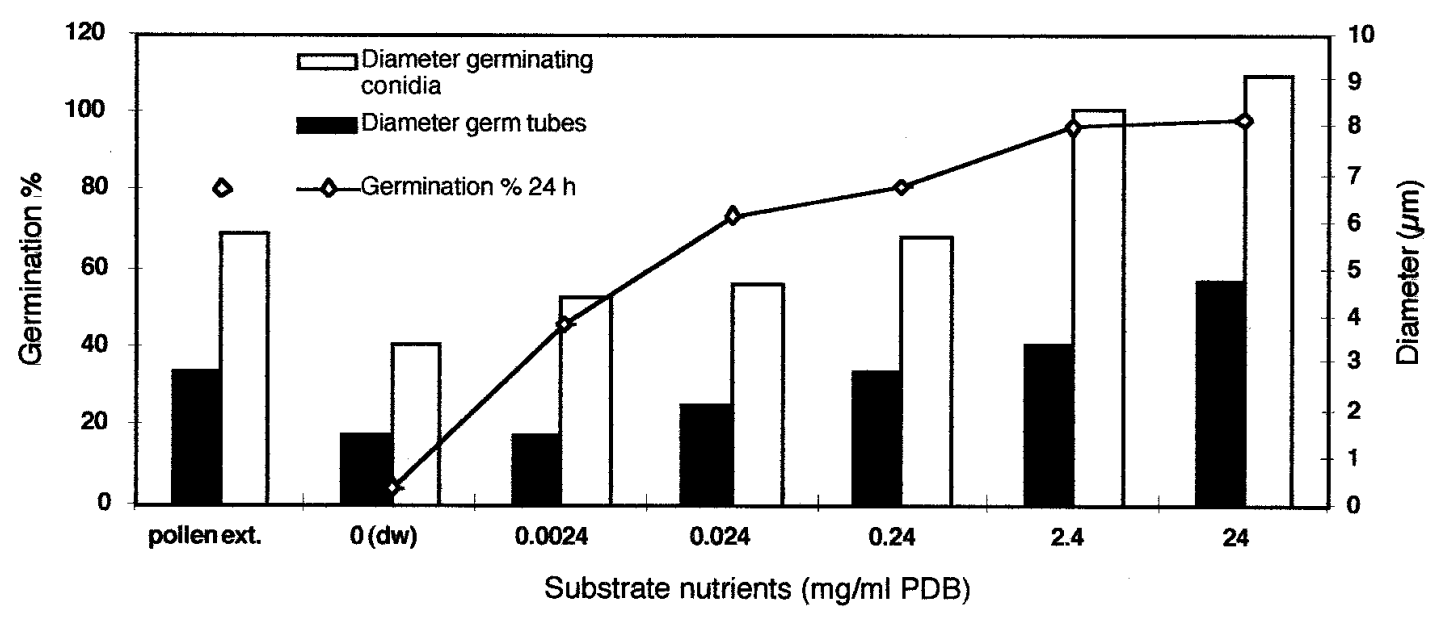

Fig. 2. Effect of substrate nutrients on germination of Trichoderma harzianum P1. Diameter of conidia at time of germination, germ tubes, and germination percent at $24 \mathrm{~h}\left(22^{\circ} \mathrm{C}\right)$ were measured in dilutions of potato dextrose broth (PDB) and in half-strength strawberry pollen extract. Data bars represent mean \pm standard error of two experiments. 
unpublished observations). To investigate how dense accumulations of $T$. harzianum conidia might affect germination of $B$. cinerea conidia in such microhabitats, various concentrations of $T$. harzianum conidia were coinoculated with $B$. cinerea conidia in microtiter plate wells (6-mm diameter). Although the size of a water drop on a plant surface is affected by factors such as hydrophobicity, surface angle, and topography, 10- to 20- $\mu$ d drops typically collected between stamens and on petals on newly opened strawberry flowers sprayed to runoff. A $20-\mu$ drop on a petal had a diameter of approximately $4 \mathrm{~mm}$. Because most $B$. cinerea and $T$. harzianum conidia settle out of suspension, the conidia density on the floor of a 6-mm-diameter well inoculated with $50 \mu \mathrm{l}$ of a given suspension would approximately correspond to that at the base of a $20 \mu \mathrm{l}, 4$-mm-diameter drop of the same suspension. For example, a suspension containing $1 \times 10^{7} \mathrm{~T}$. harzianum conidia per ml would result in a settled density of $1.8 \times$ $10^{4}$ conidia per $\mathrm{mm}^{2}$ on the well floor or $1.6 \times 10^{4}$ conidia per $\mathrm{mm}^{2}$

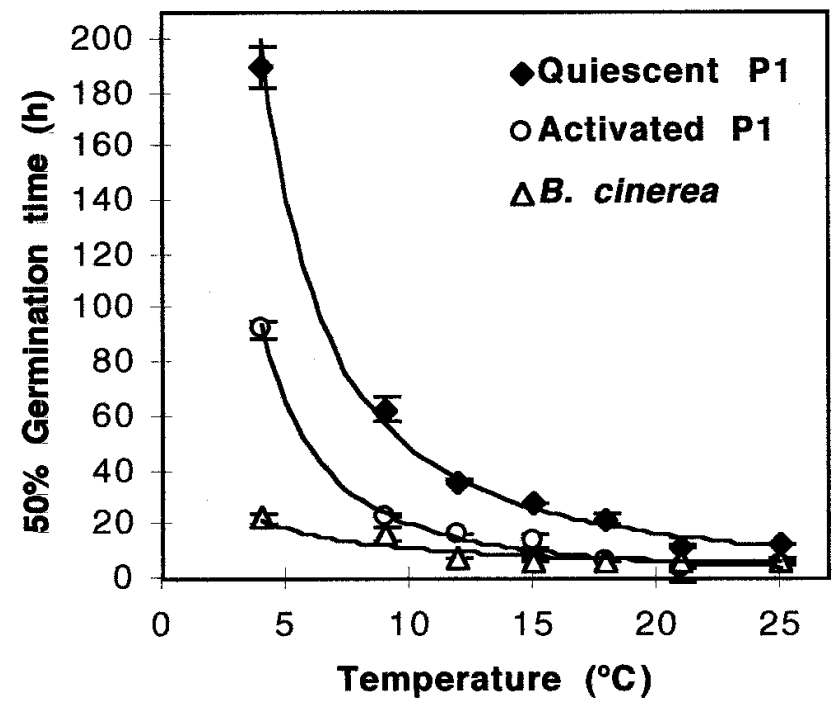

Fig. 4. Time required for $50 \%$ germination of quiescent or activated Trichoderma harzianum $\mathrm{P} 1$ conidia or Botrytis cinerea E1 conidia in axenic cultures $\left(1 \times 10^{5} \mathrm{ml}^{-1}\right)$ at different temperatures. Data points represent mean \pm standard error of three experiments.

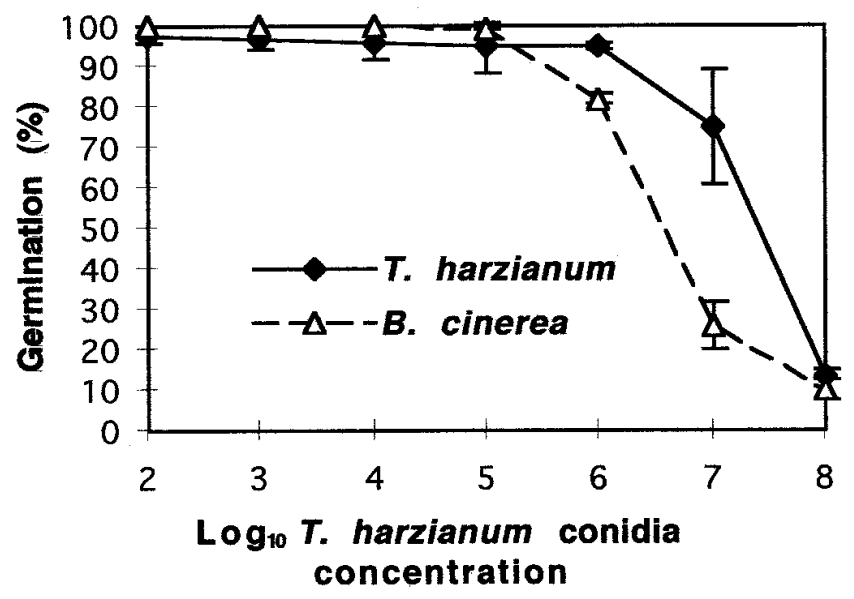

Fig. 5. In vitro germination of Trichoderma harzianum $\mathrm{P} 1$ and Botrytis cinerea $\mathrm{E} 1$ in still microtiter plate cultures containing different concentrations of $T$. harzianum conidia. Data points for $T$. harzianum germination are means and standard error of three experiments on axenic cultures inoculated with quiescent conidia. Data points for $B$. cinerea germination are means and standard errors of two experiments in which $B$. cinerea conidia $\left(1 \times 10^{5} \mathrm{ml}^{-1}\right)$ were coinoculated with quiescent conidia of $T$. harzianum $\mathrm{P} 1$ at the concentrations indicated. Incubation temperature $23 \pm 2^{\circ} \mathrm{C}$. at the bottom of a 4-mm drop on a petal. This is a dense concentration of conidia that come in physical contact with each other as they swell.

The effect of such conidia accumulation on germination of the fungi in vitro was studied on $B$. cinerea and T. harzianum conidia settled on the bottom of microtiter plate wells, with PDB as a nutrient source (Fig. 5). It was found that the germination percentage

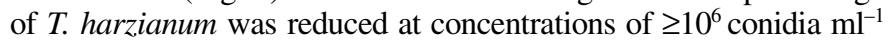
( $F$ was significant at $P=0.006$ ), and in mixed cultures, the same antagonist concentrations negatively affected germination of $B$. cinerea conidia ( $F$ was significant at $P=0.002$ ).

$B$. cinerea germination in mixed cultures in which both incubation temperature and concentration of $T$. harzianum conidia were varied is illustrated in Figure 6. Analysis of variance showed that the results of interactions between $B$. cinerea and $T$. harzianum conidia were significantly affected by both temperature $(P=0.04)$ and concentration of the antagonist $(P=0.02)$ when the latter was quiescent at time of inoculation (Fig. 6A). In contrast, temperature was not a significant source of variation when the antagonist conidia were activated by nutrients before being coinoculated with the pathogen conidia (Fig. 6B). Inoculum concentration of nutrient-activated antagonist conidia accounted for the effect on
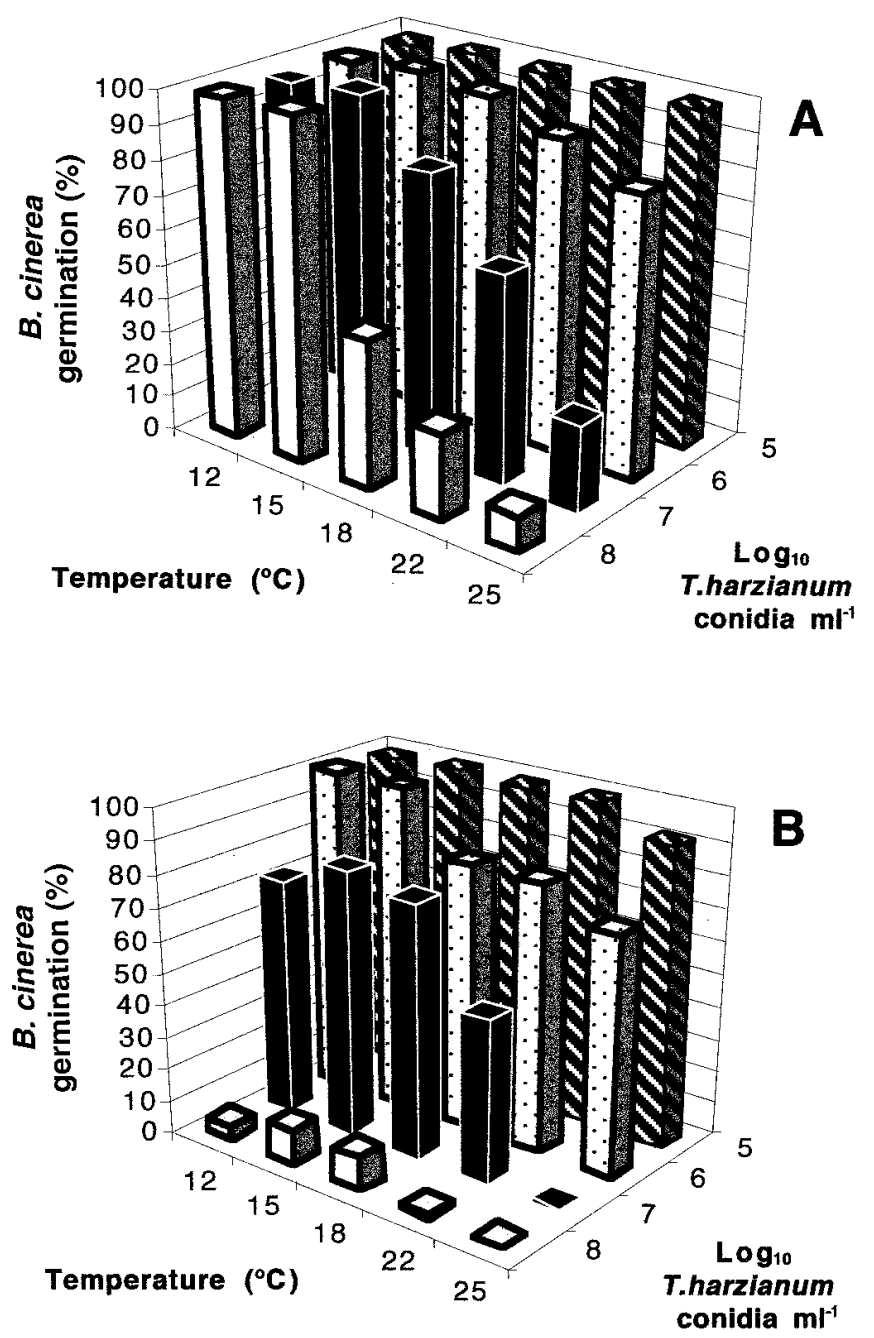

Fig. 6. Effect of antagonist inoculum concentration and incubation temperature on germination of Botrytis cinerea conidia coinoculated in potato dextrose broth with A, quiescent or B, activated Trichoderma harzianum P1 conidia. Germination was evaluated $24 \mathrm{~h}$ after inoculation. One-hundred percent germination of $B$. cinerea conidia $\left(1 \times 10^{5} \mathrm{ml}^{-1}\right.$ in all suspensions) was achieved at all temperatures in the absence of $T$. harzianum conidia or at $T$. harzianum concentrations $<10^{5} \mathrm{ml}^{-1}$. Data bars are mean germination of two replicates of 100 randomly chosen conidia. 
germination of the pathogen $(P=<0.0001)$. Suppression of $B$. cinerea germination $(\mathrm{GBc})$ by the three highest concentrations of quiescent conidia was directly dependent on temperature $(T)$ : at $10^{8} \mathrm{P} 1$ conidia $\mathrm{ml}^{-1}, \mathrm{GBc}=-7.708 T+197.3(P=0.01)$; at $10^{7} \mathrm{ml}^{-1}$, $\mathrm{GBc}=-5.589 T+176.8(P=0.01) ;$ and at $10^{6} \mathrm{ml}^{-1}, \mathrm{GBc}=$ $-1.280 T+117.6(P=0.02)$ (Fig. 6A). When activated before inoculation, $\mathrm{P} 1$ conidia at a concentration of $10^{8} \mathrm{ml}^{-1}$ were not dependent on temperature to effectively suppress $B$. cinerea germination. Less concentrated inocula of activated conidia suppressed $B$. cinerea germination more effectively at higher temperatures: at $10^{7}$ activated $\mathrm{P} 1$ conidia $\mathrm{ml}^{-1}, \mathrm{GBc}=-5.407 T+156.5(P=0.05)$; and at $10^{6} \mathrm{ml}^{-1}, \mathrm{GBc}=-2.16 T+127.0(P=0.01)($ Fig. 6B).

When inoculated at the two highest concentrations, activated $T$. harzianum conidia were significantly more effective than quiescent conidia in inhibiting $B$. cinerea germination at all temperatures (PLSD, $P \leq 0.04$ ), except at a concentration of $10^{7}$ conidia per $\mathrm{ml}$ at $22^{\circ} \mathrm{C}$. Although the germination shown was measured at $24 \mathrm{~h}$, it did not increase after this time unless the cultures were manipulated.

In those cultures in which germination was detected, germ tube extension from germinated $B$. cinerea conidia was inhibited by both fresh and activated T. harzianum conidia at concentrations of $\geq 10^{6}$ per ml (data not shown). As seen previously (Fig. 5), germination of the antagonist was also inhibited in dense suspensions. However, because of the large numbers of $T$. harzianum conidia present, even a low germination percentage resulted in mycelial growth of the antagonist similar to that seen in noninhibited cultures when conditions were otherwise conducive to germination. Mycelial establishment of $B$. cinerea was never detected in severely inhibited cultures, even after extended incubation.

The cause of the germination inhibition in dense conidial suspensions was investigated as follows. Ten-microliter aliquots containing medium and conidia were removed from mixed cultures that had been incubated $24 \mathrm{~h}$ without significant germination $\left(10^{8}\right.$ activated $T$. harzianum $\mathrm{P} 1$ per $\mathrm{ml}$ plus $10^{5} \mathrm{~B}$. cinerea per $\mathrm{ml}$ incubated at $25^{\circ} \mathrm{C}$ [Fig. 6B]). When the aliquots were placed in new wells without the addition of nutrients or water, germination of both $T$. harzianum and B. cinerea increased rapidly. Within $4 \mathrm{~h}$, the previously inhibited $B$. cinerea conidia reached $100 \%$ germination and many of the swollen but ungerminated T. harzianum conidia proceeded to germinate. Germination also increased in the well from which the aliquot had been removed, whereas germination did not change in parallel wells from which no conidia were removed. No changes were made in the test suspensions other than increased dispersal of conidia when the small aliquots were spread over the surface of new wells and aeration of both suspensions as a result of aliquot transfer. In a second experiment, all conidia were removed from inhibitory and noninhibitory suspensions by centrifugation and the supernatants were inoculated with fresh conidia of $B$. cinerea and $T$. harzianum (each in a final concentration of $1 \times 10^{5} \mathrm{ml}^{-1}$ ), without the addition of nutrients. At this lower concentration, the conidia germinated completely

TABLE 1. Germination of Botrytis cinerea in suspensions of Trichoderma harzianum $\mathrm{P} 1$ in potato dextrose broth before and after reduction of $T$. harzianum conidia density

\begin{tabular}{lcc}
\hline & \multicolumn{2}{c}{$\%$ B. cinerea germination $^{\mathrm{y}}$} \\
\cline { 2 - 3 } $\begin{array}{l}\text { Antagonist coinoculated } \\
\text { with } B \text {. cinerea }(\text { per } \mathrm{ml})^{\mathrm{x}}\end{array}$ & $\begin{array}{c}\text { In original } \\
\text { suspension }\end{array}$ & $\begin{array}{c}\text { After removal and } \\
\text { replacement of conidia }\end{array}$ \\
\hline $10^{8}$ activated P1 & $0.3 \pm 0.3$ & $98 \pm 1.1$ \\
$10^{5}$ activated P1 & $92 \pm 1.5$ & $97 \pm 1.5$ \\
$10^{8}$ quiescent P1 & $9.3 \pm 2.6$ & $100 \pm 0$ \\
$10^{5}$ quiescent P1 & $99 \pm 0.67$ & $100 \pm 0$ \\
\hline
\end{tabular}

${ }^{x}$ Final concentration of $B$. cinerea conidia in all suspensions was $1 \times 10^{5}$ conidia per $\mathrm{ml}$.

y Mean of three replicates \pm standard error.

${ }^{\mathrm{z}}$ Final concentration of $T$. harzianum conidia was $1 \times 10^{5}$ per $\mathrm{ml}$. within $24 \mathrm{~h}$, indicating that nutrient depletion or build-up of toxic metabolites in the medium had not caused the germination inhibition seen in the original suspension (Table 1).

Taken together, these results suggest that the germination inhibition seen in dense conidia suspensions was a fungistatic effect of lack of oxygen or build-up of $\mathrm{CO}_{2}$ in the immediate vicinity of the swelling conidia. T. harzianum P1 conidia that had already initiated germination processes at the time of inoculation produced a more inhibitory suspension than quiescent conidia (Fig. 6), even without germinating (Fig. 5). Inhibition of B. cinerea germination by both activated and initially quiescent $\mathrm{P} 1$ conidia increased with temperature (Fig. 6), as did speed of germination (Fig. 4). The volatile nature of the inhibitory factor was suggested by the observation that agitation and dispersal of the conidia was sufficient and necessary to permit germination to proceed (Table 1).

Effect of $T$. harzianum $P 1$ application on $B$. cinerea infection of strawberries in the field and greenhouse. A field trial was designed to test whether application of quiescent or activated $T$. harzianum P1 conidia was able to reduce $B$. cinerea infection of strawberry flowers. Flowers were tagged according to four different phenological stages and were sprayed to runoff with $B$. cinerea $\mathrm{E} 1$ conidia and fresh or activated $T$. harzianum $\mathrm{P} 1$ conidia. The mean air temperature was $13.5^{\circ} \mathrm{C}$ the day of treatment application and did not exceed $15.8^{\circ} \mathrm{C}$ during the following 4 days. The field was harvested six times after treatment. The tagged flowers made it possible to determine the approximate phenological stage at which each crop of ripe berries had been treated, as well as that of the individual tagged berries. There were no significant treatment effects on total weight of harvest or percent by weight of healthy berries in the crops resulting from treatments applied when the majority of flowers were senescing or older (data not shown). At the time of the sixth and final harvest, when berries treated as open flowers and buds became ripe, the crop was so heavily damaged by rain that only the remaining tagged berries were harvested and registered.

Analysis of the tagged berries showed that inoculation with conidia of T. harzianum $\mathrm{P} 1$ and $B$. cinerea or both had no effect on the percentage of healthy berries when applied to flowers before or after the newly opened flower stage (Table 2). Even flowers treated shortly after this stage, i.e., when the petals were dropping, showed no effect of treatments. However, application of nutrientactivated conidia of $T$. harzianum P1 to flowers at the newly opened flower stage resulted in a significant increase in the percentage of healthy berries compared with treatments with water alone $(P=0.01)$, with $B$. cinerea alone $(P=0.0005)$, or with $B$. cinerea and nonactivated $T$. harzianum $\mathrm{P} 1$ conidia $(P=0.01)$ (Table 2).

In the greenhouse trial, plants were treated as in the field trial, with the exception that all newly opened flowers were treated by spraying at 3-day intervals throughout the blossoming period. The

TABLE 2. Percentage of healthy strawberries at harvest following a single treatment with quiescent or nutrient-activated Trichoderma harzianum P1 conidia and Botrytis cinerea conidia applied to flowers tagged at different phenological stages ${ }^{\mathrm{z}}$

\begin{tabular}{lcccc}
\hline $\begin{array}{l}\text { Developmental } \\
\text { stage treated }\end{array}$ & $\begin{array}{c}\text { Uninoculated } \\
\text { control }\end{array}$ & B. cinerea & $\begin{array}{c}\text { Quiescent P1 } \\
+B \text {. cinerea }\end{array}$ & $\begin{array}{c}\text { Activated P1 } \\
+B \text {. cinerea }\end{array}$ \\
\hline $\begin{array}{l}\text { Bud } \\
\text { Newly opened }\end{array}$ & $25.0 \pm 9.6 \mathrm{a}$ & $30.0 \pm 4.3 \mathrm{a}$ & $26.7 \pm 7.2 \mathrm{a}$ & $26.7 \pm 6.1 \mathrm{a}$ \\
$\quad$ flower & $33.3 \pm 4.7 \mathrm{~b}$ & $25.0 \pm 1.7 \mathrm{~b}$ & $33.3 \pm 4.7 \mathrm{~b}$ & $48.3 \pm 1.6 \mathrm{c}$ \\
$\begin{array}{l}\text { Senescing } \\
\quad \text { flower }\end{array}$ & $35.0 \pm 8.8 \mathrm{~d}$ & $30.0 \pm 8.4 \mathrm{~d}$ & $33.3 \pm 3.8 \mathrm{~d}$ & $31.7 \pm 6.9 \mathrm{~d}$ \\
Green fruit & $43.3 \pm 10.4 \mathrm{e}$ & $50.0 \pm 13.5 \mathrm{e}$ & $41.7 \pm 7.4 \mathrm{e}$ & $53.3 \pm 2.7 \mathrm{e}$ \\
\hline
\end{tabular}

$\overline{\mathrm{z}}$ All data are means \pm standard error of four replicates. Different flower stages (rows) were analyzed separately, because of different harvest times and environmental conditions. Treatment means in each row followed by the same letter are not significantly different (Fisher's protected least significant difference, $P<0.05)$. 
mean daily temperature during the treatment period was $18.6^{\circ} \mathrm{C}$ and it remained above $18^{\circ} \mathrm{C}$ throughout the harvest period. Registration at harvest showed little fruit decay and no significant effect of treatments (data not shown). Incubation of symptomless berries under disease-promoting conditions, however, revealed that inoculation of open flowers with $B$. cinerea significantly increased the amount of latent infection (PLSD, $P=0.02$ [Fig. 7A], $P=0.003$ [Fig. 7B]). When flowers inoculated with the pathogen were also treated with $T$. harzianum conidia, disease was reduced to a level not significantly different from the uninoculated controls ( $P=0.10$ [Fig. 7A], $P=0.24$ [Fig. 7B]). There was no significant difference between the efficacy of activated and initially quiescent T. harzianum conidia.

Survival of T. harzianum P1 on treated flowers and fruits. To monitor colonization ability of the antagonist, flowers and apparently healthy berries were collected from the greenhouse and field trials at various times after treatment with $T$. harzianum conidia and incubated in moist chambers to promote sporulation of the antagonist. No sign of Trichoderma sporulation was seen on any samples at the time of collection. When treated flowers were collected in the greenhouse and field the day after conidia appli-
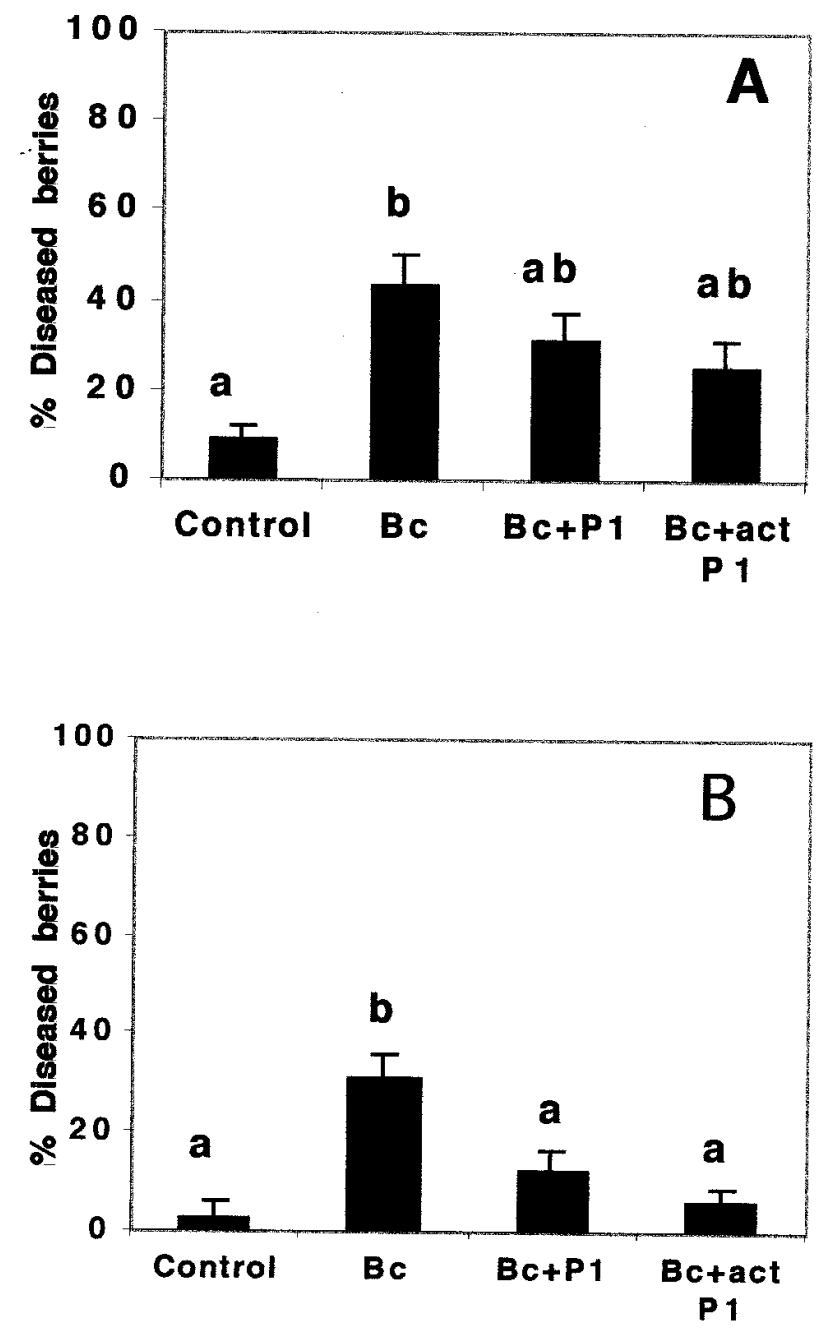

Fig. 7. Latent infection in greenhouse-grown strawberries following sprays to runoff during flowering with conidia of Trichoderma harzianum $\left(5 \times 10^{7} \mathrm{ml}^{-1}\right)$ and Botrytis cinerea $\left(1 \times 10^{5} \mathrm{ml}^{-1}\right)$. Control: sprayed with water; Bc: sprayed with $B$. cinerea and water; $\mathrm{Bc}+\mathrm{P} 1$ : sprayed with $B$. cinerea and quiescent conidia of $T$. harzianum $\mathrm{P} 1$; and $\mathrm{Bc}+$ act.P1: sprayed with $B$. cinerea and activated conidia of $T$. harzianum $\mathrm{P} 1$. Four replicates of ten symptomless berries from each treatment were taken from the $\mathbf{A}$, first and $\mathbf{B}$, third harvests and incubated at 22 to $24^{\circ} \mathrm{C}$ in moist chambers for 3 days. Bars show means \pm standard error of replicates; bars with different letters are significantly different (Fisher's protected least significant difference, $P<0.05$ ). cation and placed in moist chambers, copious Trichoderma sporulation developed on anthers of all flowers treated with activated or quiescent conidia, indicating that the conidia had survived the application process and were germinable under conducive conditions. After 4 days in the greenhouse, a mean ( \pm standard error) of $80 \pm 6 \%$ of the treated flowers showed Trichoderma sporulation after incubation. After 8 and 10 days in the greenhouse, Trichoderma sporulation was detectable on $39 \pm 2.5 \%$ and $15 \pm 0.5 \%$ of the treated flowers, respectively. No sporulation was detectable after incubation of ripe berries that had been treated as flowers, although berry washes revealed a mean of 1 to $10 \times 10^{3}$ Trichoderma CFU per berry (data not shown). There were no consistent differences between berries treated with quiescent and activated conidia. Two weeks after treatment in the field, ripe berries that had been sprayed with conidia as immature fruit were similarly incubated. No signs of Trichoderma sporulation were seen on the fruit. After the last harvest, tagged berries that had been treated as open flowers with $T$. harzianum conidia 39 days previously were similarly incubated. No signs of the antagonist were seen before or after incubation. These results indicate that conidia of the antagonist were not germinable on the fruit following extended exposure to field or greenhouse conditions.

\section{DISCUSSION}

The laboratory, greenhouse, and field experiments demonstrated that $T$. harzianum $\mathrm{P} 1$ conidia were capable of preventing coinoculated conidia of $B$. cinerea from infecting newly opened strawberry flowers. The time frame involved indicated that effective antagonism occurred before or immediately after germination of the introduced conidia of both fungi, and in vitro experiments suggested a previously undescribed antagonistic mechanism consistent with these results as well as those of previously reported field trials.

The key role of substrate nutrients in the relevant interactions was suggested by the inability of either fungus to effectively colonize flower stages in which fresh pollen was unavailable. Germination and flower infection by $B$. cinerea are enhanced by pollen $(3,7,28)$, and pollen also induced germination of T. harzianum $\mathrm{P} 1$ conidia. When quiescent $T$. harzianum and $B$. cinerea conidia come in contact with nutrients at the same time, the pathogen has the competitive advantage of a faster germination rate, particularly at low temperatures. It is well known that Trichoderma antagonists are most effective at temperatures approaching $25^{\circ} \mathrm{C}$. However, because even at these temperatures $B$. cinerea conidia are able to complete germination faster than Trichoderma conidia, effective inhibition must occur while the antagonist conidia are still ungerminated. The present results demonstrated that at conducive temperatures, sufficiently concentrated inocula of initially quiescent $T$. harzianum conidia were capable of inhibiting in vitro germination of $B$. cinerea conidia on nutrient substrates. At lower temperatures, however, preliminary initiation of germination processes in the antagonist conidia was necessary for effective antagonism.

The importance of applying a highly concentrated antagonist inoculum has not previously been explained satisfactorily. The present results suggest that this may be related to development of an inhibitory microenvironment by the increasing respiration of conidia following initiation of germination $(37,46)$. Germination of $B$. cinerea decreases linearly with increasing amounts of $\mathrm{CO}_{2}$ (58), whereas Trichoderma spp. are relatively insensitive to low oxygen and high $\mathrm{CO}_{2}$ levels, perhaps reflecting their adaptation to a soil habitat $(6,11,33)$. Oxygen consumption by conidia of many fungi increases linearly with time as germination progresses $(19,35)$. The observation that $T$. harzianum $\mathrm{P} 1$ conidia inhibited in vitro germination of $B$. cinerea more effectively at a near-optimal $25^{\circ} \mathrm{C}$ than at 18 or $12^{\circ} \mathrm{C}$ is consistent with a more rapidly increasing conidial respiratory rate at the higher temperature. The 
same temperature pattern was described for effective antagonism by $T$. harzianum toward B. cinerea on grapes and cucumbers (12, 17). $T$. viride could suppress germination of $B$. cinerea on lettuce when coinoculated at $25^{\circ} \mathrm{C}$, but the antagonist had to be inoculated 2 days before the pathogen to inhibit its germination at $15^{\circ} \mathrm{C}$ (60).

Pregermination interactions do not exclude nutrient competition or suppression of secondary inoculum production as biocontrol mechanisms under environmental conditions conducive to germination and survival of the antagonist. We have regularly observed mycoparasitism by $T$. harzianum $\mathrm{P} 1$ on $B$. cinerea mycelium on fruits in moist chambers. However, we have not observed colonization of $T$. harzianum on flowers or fruits under field conditions. The lack of evidence that the antagonist retained germinability on developing fruit throughout the field and greenhouse trials as well as the improved efficacy following preliminary conidia activation suggest that early antagonistic interactions were primarily responsible for the observed disease reduction. Because flower infections occur during a limited period, antagonist conidia would not need to be ecologically competent on flower surfaces in order to be effective.

The antagonistic mechanism suggested by our results is consistent with ecological characteristics of $T$. harzianum. Regulation of germination according to substrate nutrient levels is a necessary adaptation for ruderal soil fungi such as Trichoderma (45). Furthermore, the ability to initiate and subsequently suspend spore germination processes in response to fluctuations in nutrient availability might be an adaptation allowing rapid response when conditions again become favorable for mycelial growth, i.e., a mechanism to disperse germination in time $(49,61)$. On the other hand, incompletely germinated conidia are susceptible to gradual debilitation by other microorganisms (61). It may be speculated that the apparent wastefulness of simultaneous initiation of germination in excessive numbers of Trichoderma conidia in the same microenvironment is actually a natural competitive mechanism to suppress other microorganisms in a manner similar to that seen in the present investigation. Trichoderma spp. are capable of producing copious amounts of conidia, and the competitive advantage accruing the few conidia completing germinating might outweigh the added energetic costs of reproduction for the population as a whole. It may be further speculated that simultaneous germination initiation could be a mechanism to select those conidia genetically or physiologically best suited to exploitation of the substrate in question.

There are several practical implications of these results relevant to Trichoderma-based biocontrol programs. In applications aimed specifically at prevention of blossom infection, concentrated inocula of antagonist conidia should be applied to all newly opened flowers, i.e., a treatment strategy based on frequent reapplication of high density inocula rather than protection by spread of a colonized antagonist $(18,36)$. To induce rapid germination initiation, quiescent antagonist conidia should be applied during a period in which temperatures remain conducive to germination for at least several hours. At suboptimal temperatures, activation of conidia before application should enhance the competitive capacity of the antagonist. Furthermore, selection of a Trichoderma isolate for such applications could be based on specific physiological traits, e.g., speed and synchronism of germination rather than more diffuse characteristics such as ecological competence, which may be important for other applications based on antagonist colonization of specific habitats. An ecologically incompetent antagonist might in fact be desirable for application on edible plant products. With regard to physiological improvement of the antagonist's activity, formulations and delivery protocols could be optimized toward application of activated conidia. "Endogenous formulation" of Trichoderma conidia, in which the only nutrients introduced into the environment are those absorbed by the antagonist before application, might be a way of avoiding the unintended stimulation of the pathogen sometimes seen following nutrient amendments in formulations applied to nonsterile plant surfaces $(22,29,53,57)$.

In summary, the present results suggest that the ability of $T$. harzianum conidia to successfully prevent flower infection by $B$. cinerea may involve production of an inhibitory microenvironment by large numbers of conidia increasing respiration upon initiating germination on a nutrient-rich substrate. Such a biocontrol mechanism is consistent with previous observations on the importance of nutrient availability, conducive temperatures, and concentrated inocula for effective disease suppression by Trichoderma isolates. Furthermore, it offers an explanation for the observed ability of Trichoderma antagonists to prevent germination of competing conidia when coinoculated at near-optimal temperatures, whereas efficacy at lower temperatures necessitates prior introduction. Inhibition of $B$. cinerea germination by incompletely germinated $T$. harzianum conidia is admittedly proposed based on observations on conidia germinating in nutrient solutions in vitro. However, because $B$. cinerea germination and flower infection are dependent on the presence of free water and available nutrients $(5,16,27)$, it appears that disease reduction in the field could result from similar interactions between conidia accumulating on newly opened flowers. Activation of antagonist conidia prior to application might be a method of improving the consistency of biocontrol programs. The demonstrated ability of $T$. harzianum conidia to inhibit B. cinerea germination before, or without, completing their own germination could explain the often observed but puzzling ability of this antagonist to control disease on plant surfaces without leaving evidence of mycelial colonization of the substrate.

\section{ACKNOWLEDGMENTS}

Financial support was provided by the Agricultural Department of the County Governor for Østfold, Norway, and the Norwegian Industrial and Regional Development Fund. We thank I. Grimsby, S. Grimsby, E. Stensrud, and H. B. Stensrud for the use of plants in their commercial facilities for our greenhouse and field trials, R. Olsen and K. Peters for useful comments on the manuscript, and O. Elen for checking the statistical aspects.

\section{LITERATURE CITED}

1. Beagle-Ristaino, J. E., and Papavizas, G. C. 1985. Survival and proliferation of propagules of Trichoderma spp. and Gliocladium virens in soil and in plant rhizospheres. Phytopathology 75:729-732.

2. Bhatt, D. D., and Vaughan, E. K. 1962. Preliminary investigations on biological control of gray mold (Botrytis cinerea) of strawberries. Plant Dis. Rep. 46:342-345.

3. Borecka, H., and Millikan, D. F. 1973. Stimulatory effect of pollen and pistillate parts of some horticultural species upon the germination of Botrytis cinerea spores. Phytopathology 63:1431-1432.

4. Bristow, P. R., McNicol, R. J., and Williamson, B. 1986. Infection of strawberry flowers by Botrytis cinerea and its relevance to grey mould development. Ann. Appl. Biol. 109:545-554.

5. Bulger, M. A., Ellis, M. A., and Madden, L. V. 1987. Influence of temperature and wetness duration on infection of strawberry flowers by Botrytis cinerea and disease incidence of fruit originating from infected flowers. Phytopathology 77:1225-1230.

6. Burges, A., and Fenton, E. 1953. The effect of carbon dioxide on the growth of certain soil fungi. Trans. Br. Mycol. Soc. 36:104-108.

7. Chou, M. C., and Preece, T. F. 1968. The effect of pollen grains on infections caused by Botrytis cinerea Fr. Ann. Appl. Biol. 62:11-22.

8. Cook, R. J., and Baker, K. F. 1983. The Nature and Practice of Biological Control of Plant Pathogens. The American Phytopathological Society, St. Paul, MN.

9. Cooley, D. R., Wilcox, W. F., Kovach, J., and Schloemann, S. G. 1996. Integrated pest management programs for strawberries in the northeastern United States. Plant Dis. 80:228-237.

10. Danielson, R. M., and Davey, C. B. 1973. Non nutritional factors affecting the growth of Trichoderma in culture. Soil Biol. Biochem. 5:495-504.

11. Danielson, R. M., and Davey, C. B. 1973. Effects of nutrients and acidity 
on phialospore germination of Trichoderma in vitro. Soil Biol. Biochem. 5:517-524.

12. d'Enfert, C. 1997. Fungal spore germination: Insights from the molecular genetics of Aspergillus nidulans and Neurospora crassa. Fungal Genet. Biol. 21:163-172.

13. Dubos, B. 1987. Fungal antagonism in aerial agrobiocenoses. Pages 107135 in: Innovative Approaches to Plant Disease Control. I. Chet, ed. John Wiley \& Sons, New York.

14. Elad, Y., Chet, I., and Henis, Y. 1981. A selective medium for improving quantitative isolation of Trichoderma spp. from soil. Phytoparasitica 9:59-67.

15. Elad, Y., and Kirshner, B. 1993. Survival in the phylloplane of an introduced biocontrol agent (Trichoderma harzianum) and populations of the plant pathogen Botrytis cinerea as modified by abiotic conditions. Phytoparasitica 21:303-313.

16. Elad, Y., and Yunis, H. 1993. Effect of microclimate and nutrients on development of cucumber gray mold (Botrytis cinerea). Phytoparasitica 21:257-268.

17. Elad, Y., Zimand, G., Zaqs, Y., Zuriel, S., and Chet, I. 1993. Use of Trichoderma harzianum in combination or alternation with fungicides to control cucumber gray mould (Botrytis cinerea) under commercial greenhouse conditions. Plant Pathol. 42:324-332.

18. Fokkema, N. J. 1995. Strategies for biocontrol of foliar fungal diseases. Pages 69-79 in: Environmental Biotic Factors in Integrated Plant Disease Control. M. Manka, ed. The Polish Phytopathological Society, Poznan.

19. Gottlieb, D. 1976. Carbohydrate metabolism and spore germination. Pages 141-163 in: The Fungal Spore, Form and Function. D. J. Weber and W. M. Hess, eds. John Wiley \& Sons, New York.

20. Griffin, D. 1981. Spore dormancy and germination. Pages 260-280 in: Fungal Physiology. D. Griffin, ed. John Wiley \& Sons, New York.

21. Harman, G. E. 2000. Myths and dogmas of biocontrol: Changes in perceptions derived from research on Trichoderma harzianum T-22. Plant Dis. 84:377-392.

22. Harman, G. E., Chet, I., and Baker, R. 1981. Factors affecting Trichoderma hamatum applied to seeds as a biocontrol agent. Phytopathology 71:569-572.

23. Hjeljord, L. G., Stensvand, A., and Tronsmo, A. 2000. Effect of temperature and nutrient stress on the capacity of commercial Trichoderma products to control Botrytis cinerea and Mucor piriformis in greenhouse strawberries. Biol. Control 19:149-160.

24. Hong, C. X., Michailides, T. J., and Holtz, B. A. 1998. Effects of wounding, inoculum density, and biological control agents on postharvest brown rot of stone fruits. Plant Dis. 82:1210-1216.

25. Howell, C. R. 1998. The role of antibiosis in biocontrol. Pages 173-184 in: Trichoderma and Gliocladium: Enzymes, Biological Control and Commercial Applications. G. E. Harman and C. P. Kubicek, eds. Taylor \& Francis, London.

26. Jarvis, W. R. 1962. The infection of strawberry and raspberry fruits by Botrytis cinerea Fr. Ann. Appl. Biol. 50:569-575.

27. Jarvis, W. R. 1964. The effect of some climatic factors on the incidence of grey mould of strawberry and raspberry fruit. Hort. Res. 3:65-71.

28. Jarvis, W. R., and Borecka, H. 1968. The susceptibility of strawberry flowers to infection by Botrytis cinerea. Hort. Res. 8:147-154.

29. Kelley, W. D. 1976. Evaluation of Trichoderma harzianum-impregnated clay granules as a biocontrol of Phytophthora cinnamomi causing damping-off of pine seedlings. Phytopathology 66:1023-1027.

30. Kullnig, C. M., Krupica, T., Woo, S. L., Mach, R. L., Rey, M., Benítez, T., Lorito, M., and Kubicek, C. P. 2001. Confusion abounds over identities of Trichoderma biocontrol isolates. Mycol. Res. 105:770-772.

31. Lifshitz, R., Windham, M. T., and Baker, R. 1986. Mechanism of biological control of preemergence damping-off of pea by seed treatment with Trichoderma spp. Phytopathology 76:720-725.

32. Lorito, M. 1998. Chitinolytic enzymes and their genes. Pages 73-99 in: Trichoderma and Gliocladium. G. E. Harman and C. P. Kubicek, eds. Taylor \& Francis, London.

33. Macauley, B. J., and Griffin, D. M. 1969. Effects of carbon dioxide and oxygen on the activity of some soil fungi. Trans. Br. Mycol. Soc. 53:53-62.

34. Mach, R. L., Peterbauer, C. K., Payer, K., Jaksits, S., Woo, S. L., Zeilinger, S., Kullnig, C. M., Lorito, M., and Kubicek, C. P. 1999. Expression of two major chitinase genes of Trichoderma atroviride ( $T$. harzianum P1) is triggered by different regulatory signals. Appl. Environ. Microbiol. 65:1858-1863.

35. Mandels, G. R. 1965. Kinetics of fungal growth. Pages 599-612 in: The Fungi. An Advanced Treatise. G. C. Ainsworth and A. S. Sussman, eds. Academic Press, New York.
36. Marois, J. J., and Coleman, P. M. 1995. Ecological succession and biological control in the phyllosphere. Can. J. Bot. 73(suppl.):S76-S82.

37. Martin, J. F., and Nicolas, G. 1970. Physiology of spore germination in Penicillium notatum and Trichoderma lignorum. Trans. Br. Mycol. Soc. 55:141-148.

38. Mitchell, C. P., and Dix, N. J. 1975. Growth and germination of Trichoderma spp. under the influence of soil fungistasis. Trans. Br. Mycol. Soc. 64:235-241.

39. Nelson, E. B. 1991. Current limits to biological control of fungal phytopathogens. Pages 327-355 in: Handbook of Applied Mycology: Soil and Plants. D. K. Arora, B. Rai, D. G. Mukerji, and G. R. Knudsen, eds. Marcel Dekker, Inc., New York.

40. Nelson, E. B., Harman, G. E., and Nash, G. T. 1988. Enhancement of Trichoderma-induced biological control of Pythium seed rot and preemergence damping-off of peas. Soil Biol. Biochem. 20:145-150.

41. Newhook, F. J. 1951. Microbiological control of Botrytis cinerea Pers. II. Antagonism by fungi and Actinomycetes. Ann. Appl. Biol. 38:185202.

42. O’Neill, T. M., Niv, A., Elad, Y., and Shtienberg, D. 1996. Biological control of Botrytis cinerea on tomato stem wounds with Trichoderma harzianum. Eur. J. Plant Pathol. 102:635-643.

43. Papavizas, G. C. 1985. Trichoderma and Gliocladium: Biology, ecology, and potential for biocontrol. Annu. Rev. Phytopathol. 23:23-54.

44. Paustian, K., and Schnürer, J. 1987. Fungal growth response to carbon and nitrogen limitation: A theoretical model. Soil Biol. Biochem. 19: 613-620.

45. Pugh, G. J. F. 1980. Strategies in fungal ecology. Trans. Br. Mycol. Soc. 75:1-14.

46. Rosen, D., Edelman, M., Galun, E., and Danon, D. 1974. Biogenesis of mitochondria in Trichoderma viride: Structural changes in mitochondria and other spore constituents during conidium maturation and germination. J. Gen. Microbiol. 83:31-49.

47. Saethre, M. G., Orpen, H. M., and Hofsvang, T. 1999. Action programmes for pesticide risk reduction and pesticide use in different crops in Norway. Crop Prot. 18:207-215.

48. Sleesman, J. P., and Leban, C. 1978. Preserving phytopathogenic bacteria at $-70^{\circ} \mathrm{C}$ or with silica gel. Plant Dis. Rep. 62:910-912.

49. Steiner, G. W., and Lockwood, J. L. 1969. Soil fungistasis: Sensitivity of spores in relation to germination time and size. Phytopathology 59:10841092.

50. Sussman, A. S. 1966. Dormancy and spore germination. Pages 733-764 in: The Fungi. An Advanced Treatise. G. C. Ainsworth and A. S. Sussman, eds. Academic Press, New York.

51. Sutton, J. C. 1994. Biological control of strawberry diseases. Adv. Strawberry Res. 13:1-11.

52. Sutton, J. C., Li, D., Peng, G., Yu, H., Zhang, P., and ValdebenitoSanhueza, R. M. 1997. Gliocladium roseum: A versatile adversary of Botrytis cinerea in crops. Plant Dis. 81:316-328.

53. Tronsmo, A. 1986. Trichoderma used as a biocontrol agent against Botrytis cinerea rots on strawberry and apple. Sci. Rep. Agric. Univ. Norway 65:1-22.

54. Tronsmo, A. 1989. Effect of fungicides and insecticides on growth of Botrytis cinerea, Trichoderma viride and T. harzianum. Norw. J. Agric. Sci. 3:151-156.

55. Tronsmo, A., and Dennis, C. 1977. The use of Trichoderma species to control strawberry fruit rots. Neth. J. Plant Pathol. 83:449-455.

56. Wainwright, M. 1988. Metabolic diversity of fungi in relation to growth and mineral cycling in soil-a review. Trans. Br. Mycol. Soc. 90:159170 .

57. Washington, W. S., Engleitner, S., Boontjes, G., and Shanmuganathan, N. 1999. Effect of fungicides, seaweed extracts, tea tree oil, and fungal agents on fruit rot and yield in strawberry. Austr. J. Exp. Agric. 39:487494.

58. Wells, J. M., and Uota, M. 1970. Germination and growth of five fungi in low-oxygen and high-carbon dioxide atmospheres. Phytopathology 60:50-53.

59. Wilcox, W. F., and Seem, R. C. 1993. Relationship between strawberry gray mold incidence, environmental variables, and fungicide applications during different periods of the fruiting season. Phytopathology 84:264-270

60. Wood, R. K. S. 1951. The control of diseases of lettuce by the use of antagonistic organisms. I. The control of Botrytis cinerea Pers. Ann. Appl. Biol. 38:203-216.

61. Yoder, D. L., and Lockwood, J. L. 1973. Fungal spore germination on natural and sterile soil. J. Gen. Microbiol. 74:107-117. 